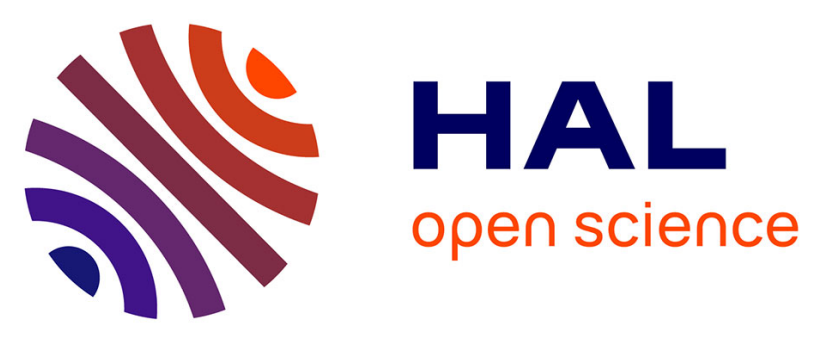

\title{
TiSnSb a new efficient negative electrode for Li-ion batteries: mechanism investigations by operando-XRD and Mossbauer techniques
}

Moulay Tahar Sougrati, Fullenwarth Julien, Aurore Debenedetti, Bernard Fraisse, Jean-Claude Jumas, Laure Monconduit

\section{To cite this version:}

Moulay Tahar Sougrati, Fullenwarth Julien, Aurore Debenedetti, Bernard Fraisse, Jean-Claude Jumas, et al.. TiSnSb a new efficient negative electrode for Li-ion batteries: mechanism investigations by operando-XRD and Mossbauer techniques. Journal of Materials Chemistry, 2011, 21, pp.10069-10076. 10.1039/C1JM10710K . hal-00606312

\section{HAL Id: hal-00606312 https://hal.science/hal-00606312}

Submitted on 6 Jul 2011

HAL is a multi-disciplinary open access archive for the deposit and dissemination of scientific research documents, whether they are published or not. The documents may come from teaching and research institutions in France or abroad, or from public or private research centers.
L'archive ouverte pluridisciplinaire HAL, est destinée au dépôt et à la diffusion de documents scientifiques de niveau recherche, publiés ou non, émanant des établissements d'enseignement et de recherche français ou étrangers, des laboratoires publics ou privés. 


\title{
TiSnSb a new efficient negative electrode for Li-ion batteries: mechanism investigations by operando-XRD and Mössbauer techniques
}

\author{
M. T. Sougrati, * J. Fullenwarth, A. Debenedetti, B. Fraisse, J. C. Jumas and L. Monconduit* \\ Received 16th February 2011, Accepted 17th March 2011 \\ DOI: 10.1039/c1jm10710k
}

We report the electrochemical study of TiSnSb towards $\mathrm{Li}$, as a negative electrode for Li-ion batteries. TiSnSb can reversibly take up more than 5 lithiums per formula unit leading to reversible capacities of $540 \mathrm{~mA} \mathrm{~h} \mathrm{~g}^{-1}$ and $4070 \mathrm{~mA} \mathrm{~h} \mathrm{~cm}{ }^{-3}$ at $2 \mathrm{C}$ rate. From complementary operando XRD and Mössbauer spectroscopy measurements, it was shown that during the first discharge the TiSnSb undergoes a conversion process leading simultaneously to the formation of $\mathrm{Li}-\mathrm{Sb}$ and $\mathrm{Li}-\mathrm{Sn}$ alloys. At the end of the discharge, $\mathrm{Li}_{3} \mathrm{Sb}$ and $\mathrm{Li}_{7} \mathrm{Sn}_{2}$ were identified. Once the first discharge is achieved, both phases were shown to form $\mathrm{Ti}-\mathrm{Sn}$ or $\mathrm{Ti}-\mathrm{Sb}$ or $\mathrm{Ti}-\mathrm{Sn}-\mathrm{Sb}$ nanocomposites. The cycling performance of $\mathrm{TiSnSb}$ was shown to be excellent with maintaining $90 \%$ of the specific capacity during 60 cycles at $2 \mathrm{C}$ rate. The good electrochemical performance of $\mathrm{TiSnSb}$ (compared to $\mathrm{Sn}$ and $\mathrm{Sb}$ ) seems to be a consequence of the presence of the non-active metal. The comparative study of Ti/Sn/Sb composite demonstrated that the structural feature of the pristine material clearly impacts both the mechanism involved during the cycling and the corresponding performance.

\section{Introduction}

Lithium rechargeable batteries present a high energy density and give various applications ranging in size from portable electronic devices to zero emission vehicles. ${ }^{1,2}$ However, and fortunately, the performances of this kind of batteries are still improvable in order to meet the growing storage demand. One of the possible ways to reach higher performance consists in finding new electrode materials. Intensive worldwide attempts have been focused on $\mathrm{Sb}^{3-7}$ and $\mathrm{Sn}$-based ${ }^{8-10}$ anode materials due to their high storage capacity. $\mathrm{Sb}$ and $\mathrm{Sn}$-based materials can react with $\mathrm{Li}$ to form $\mathrm{Li}_{3} \mathrm{Sb}$ and $\mathrm{Li}_{22} \mathrm{Sn}_{5}$ intermetallics with theoretical capacities of $660 \mathrm{~mA} \mathrm{~h} \mathrm{~g}^{-1}$ and $994 \mathrm{~mA} \mathrm{~h} \mathrm{~g}^{-1}$ respectively. ${ }^{11}$ However, the large volume expansion upon lithiation is a real limit to the commercialization of batteries containing $\mathrm{Sb}$-, and $\mathrm{Sn}$-based materials. Many efforts, therefore, have been devoted to overcome this obstacle. Related reports have revealed that reducing the size of active particles did not effectively improve the cyclability of the alloy materials in the case of $\mathrm{Sn}$, because the nanoparticles are apt to aggregate, forming inactive dense blocks after some cycles. ${ }^{12}$ The use of intermetallics or composite active/ inactive materials instead of a pure metal seems to be an effective way to control the volume changes of the alloy based electrodes. ${ }^{13}$ This is due to the so-called buffering effect of the inactive component. In the alloys where all the active

Institut Charles Gerhardt Montpellier-UMR 5253 CNRS, ALISTORE European Research Institute (3104 CNRS), Université Montpellier 2, 34095 Montpellier, France. E-mail: Moulay-Tahar.Sougrati@um2.fr; Laure.monconduit@um2.fr components can react with $\mathrm{Li}$ at different potentials in the charging/discharging process, such as $\mathrm{SnSb}$, the volume change occurs in a stepwise manner rather than at a certain fixed potential, thus the unreacted component can accommodate the strain yielded by the reacted phase. Although the cycling stability of the electrode is improved, it is still limited. Recently, the demand for stable cyclic performance of nanosized $\mathrm{SnSb}$ alloys has highly stimulated the research for nanocomposites with carbonaceous materials such as graphite, ${ }^{14} \mathrm{MCMB}^{15}$ and amorphous carbon. ${ }^{16}$ However, again the agglomeration of nanosized alloys is still considered as the predominant barrier to the practical application of these kinds of alloys. There has been also substantial interest in ternary composite alloys like $\mathrm{Cu}-\mathrm{Sn}-$ $\mathrm{Zn},{ }^{17} \mathrm{Co}-\mathrm{Sn}-\mathrm{Sb},{ }^{18} \mathrm{Sn}-\mathrm{Sb}-\mathrm{Cu}^{19}$ and $\mathrm{Sn}_{x}-\mathrm{Sb}-\mathrm{Ni}$ with $x=1$ to $3 .^{20}$ A micro-sized polyphasic $\mathrm{Sn}_{x}-\mathrm{Sb}-\mathrm{Ni}$ composite anode could retain $350 \mathrm{~mA} \mathrm{~h} \mathrm{~g}^{-1}$ after 20 cycles with limited capacity fading. The ductile component $\mathrm{Ni}$ could act as a buffer to relieve the volume change stress of the electrode.

In present work, TiSnSb (the only known ternary alloy in the system $\mathrm{Ti}-\mathrm{Sn}-\mathrm{Sb}^{\mathbf{2 1}}$ ) is prepared and investigated by various techniques. Titanium - which is electrochemically inactive, light, nontoxic and inexpensive - can increase the mechanical resistance of the electrode to the volume change and contribute to its cycling stability. The paper is organized as follows. The Experimental section describes the synthesis and chemical/physical characterizations of TiSnSb. The second part describes its electrochemical performance together with attempts to determine the reactivity mechanism as deduced by in situ X-ray and in situ ${ }^{119} \mathrm{Sn}$ Mössbauer spectral study. Finally, a composite electrode design of $\mathrm{TiSnSb}$ is reported as an improvement for long cyclability. 


\section{Experimental details}

TiSnSb has been synthesized by ball milling of $\mathrm{Ti}, \mathrm{Sn}$ and $\mathrm{Sb}$ powders from commercial sources $(>99.9 \%$ ) under Ar atmosphere using the planetary Ball Mill PM 100. For all our preparations, $1 \mathrm{~g}$ of metallic powder was used in a $50 \mathrm{ml}$ grinding jar with 6 balls ( $5 \mathrm{~g}$ each). Both the jars and the balls are made of hardened stainless steel. The active-milling time has been ranged from 10 to 30 hours.

The ball milling prepared TiSnSb (referenced as BM below) can contain some $\mathrm{SnSb}$ and/or $\mathrm{Sn}$ as impurities depending on the milling time and initial stoichiometry. The lowest impurities amount is obtained after a 24 hours milling of the three metals with a slight excess of $\mathrm{Ti}$ (exactly in the $1.1: 1: 1 \mathrm{Ti} / \mathrm{Sn} / \mathrm{Sb}$ stoichiometry). The BM-TiSnSb powder was annealed in sealed silica tubes at $450{ }^{\circ} \mathrm{C}$ (temperature ramp at $1{ }^{\circ} \mathrm{C} \mathrm{min}^{-1}$ ) under static vacuum for one week before being cooled in air. Annealed powder is referenced below as BMA. We also prepared an intimate mixture $\mathrm{Ti} / \mathrm{Sn} / \mathrm{Sb}$ in $1 / 1 / 1$ composition by a short grinding (15 min) for further electrochemical comparison.

The powdered sample was observed by scanning electron microscopy (SEM) in order to characterize both the sample morphology and the particle size (Fig. 1).

$\mathrm{X}$-Ray diffractograms were recorded using an X'pert diffractometer equipped with $(\mathrm{Cu} \mathrm{K} \alpha)$ radiation in the range $10<2 \theta<$ $90^{\circ}$ (Fig. 2). The FULLPROF software ${ }^{22}$ has been used for the profile matching of the TiSnSb diffractograms and for the calculation of its unit cell parameters.

${ }^{119} \mathrm{Sn}$ Mössbauer spectra were collected with a constant acceleration spectrometer using a $\mathrm{Ca}^{119 m} \mathrm{SnO}_{3}$ source in the transmission geometry. They were fit to combinations of Lorentzian lines. The absorber used for the determination of the hyperfine parameters contained $10 \mathrm{mg} \mathrm{cm}^{-2}$ of the TiSnSb powder. In order to optimize the counting time for the operando Mössbauer measurements, the TiSnSb quantity was doubled and hence it was possible to record good quality spectra within 85 min each.

Electrochemical lithium insertion/extraction tests were carried out with ( $\mathrm{Li}^{\mathrm{L}} \mathrm{LiPF}_{6} 1 \mathrm{M}$ (EC:PC:3DMC-VC)/TiSnSb) two-
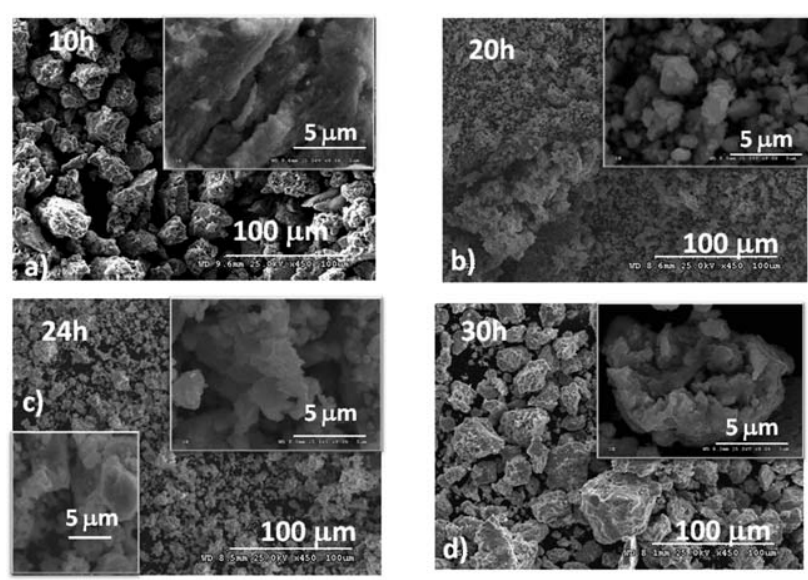

Fig. 1 SEM micrographs for TiSnSb powders prepared by BM after 10 $\mathrm{h}$ (a), $20 \mathrm{~h}$ (b), $24 \mathrm{~h}$ (c), $30 \mathrm{~h} \mathrm{(d),} \mathrm{after} 24 \mathrm{~h}$ of BM and annealing at $450{ }^{\circ} \mathrm{C}$ (left inset in (c)). Insets show the corresponding powder grain at lower magnification.

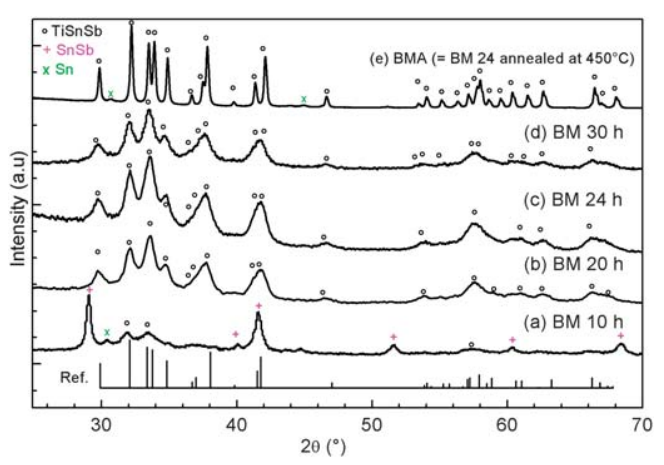

Fig. 2 XRD patterns of the as prepared powder after 25, 50, 60 and 75 hours of ball milling respectively (a) to (d). The pattern (e) is obtained after annealing powder (c) at $450{ }^{\circ} \mathrm{C}$.

electrode Swagelok ${ }^{\mathrm{TM}}$-type cells assembled inside an argon-filled glove box. Powdered electrodes were prepared by mixing $85 \mathrm{wt} \%$ of pristine materials with $15 \mathrm{wt} \%$ carbon black (CB). Electrochemical discharge/charge curves were recorded on a multichannel VMP system under galvanostatic conditions at various rates. For in situ Mössbauer and XRD measurements, a specific cell $^{23}$ has been used and the electrochemical tests have been recorded in a $C / 5$ rate $(1 \mathrm{Li}$ in $5 \mathrm{~h}$ ).

For the electrode formulation, carbon black was used as conductive additive and carboxymethyl cellulose (CMC) (DS = $0.7, M_{\mathrm{w}}=250000$ Aldrich) was used as binder. $304 \mathrm{mg}$ of TiSnSb, $77 \mathrm{mg}$ of conductive additive and $52 \mathrm{mg}$ of CMC was introduced into a vial and grinded for $1.5 \mathrm{~h}$. Deionized water $(0.8$ $\mathrm{ml}$ ) was added to the composite electrode material. The slurry was tape cast onto $200 \mu \mathrm{m}$ thick copper foil and dried for $12 \mathrm{~h}$ at room temperature and then for another $2 \mathrm{~h}$ at $100{ }^{\circ} \mathrm{C}$ under vacuum.

\section{Results and discussion}

SEM study shows that BM-TiSnSb material is made of a distribution of shapeless grains (Fig. 1). The decrease of the particle size is clearly shown between the $10 \mathrm{~h}$ milled sample and the 20 and $24 \mathrm{~h}$ milled samples. The former sample is made of 10 to 50 micrometric sized aggregates, when for the latter the aggregates are totally separated into small $0.5-1$ micrometric particles. Interestingly, when the milling time is increased to 30 hours, a reaggregation of small particles into clusters is observed. The XRD data of the BMA powder (Fig. 2) show that TiSnSb adopts the $\mathrm{Mg}_{2} \mathrm{Cu}$ type structure. The $\mathrm{Sn}$ atoms occupy the $16 \mathrm{f}$ sites while $\mathrm{Ti}$ and $\mathrm{Sb}$ atoms are located in the $16 \mathrm{~g}$ sites. The refined cell parameters are in agreement with those reported for TiSnSb in the $F d d d$ orthorhombic space group ( $a=5.5121$ (1), $b=9.8196$ (1) and $c=19.2001$ (2) $\AA$ ). ${ }^{24}$ The Mössbauer spectra of BM- and MBA-TiSnSb consist of split doublets with isomer shifts of 2.374 (5) and 2.366 (5) $\mathrm{mm} \mathrm{s}^{-1}$ and quadrupole splittings of 1.98 (1) and 2.12 (1) $\mathrm{mm} \mathrm{s}^{-1}$ respectively. The thermal evolution of these parameters, as well as the Lamb-Mössbauer factor, have been discussed in detail in ref. 25.

BM-TiSnSb/Li and BMA-TiSnSb/Li half-cells were assembled to study their electrochemical behavior. Their discharge/charge curves together with the corresponding derivatives (left column) are given in Fig. $3 \mathrm{a}$ and $\mathrm{b}$ respectively. In addition, the 

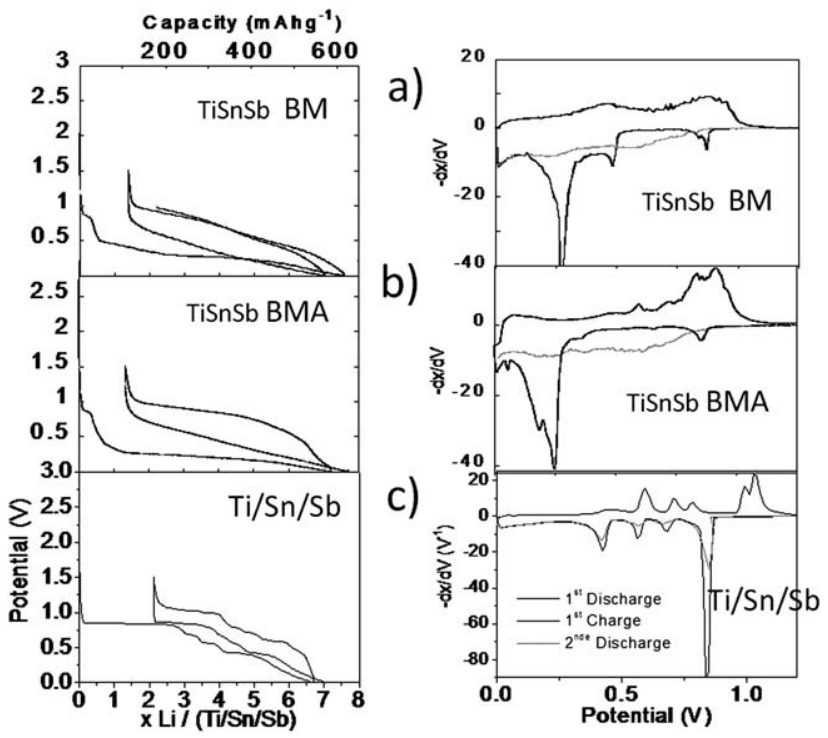

different from the BM and BMA profiles. Except for a larger polarization in the BMA curve, BMA profile is quite similar to that of BM. Upon recharge to $1.5 \mathrm{~V}, 5.5 \mathrm{Li}$ per formula unit can be removed from both BM and BMA cells leading to reversible specific capacities of 510 and $520 \mathrm{~mA} \mathrm{~h} \mathrm{~g}^{-1}$ ( 3775 and $3850 \mathrm{~mA} \mathrm{~h}$ $\mathrm{cm}^{-3}$ ) respectively and, the corresponding irreversible capacities being of $18 \%$ for both.

\section{The cycling profile}

For the second discharge (and subsequent cycles), the potential curves are identical for both BM and BMA and are characteristic of a conversion material with a higher discharge potential than for the first discharge curve. The derivative peaks of subsequent cycles become very broad and badly defined as usually observed for many conversion materials. ${ }^{26-29}$

\section{Cycling performances}

Fig. 3 Composition-voltage profile and the corresponding derivative for (a) BM-TiSnSb/Li, (b) BMA-TiSnSb/Li and (c) $(\mathrm{Ti} / \mathrm{Sn} / \mathrm{Sb}$ )/Li cells cycled at $C / 10$ rate between 1.5 and $0 \mathrm{~V}$.

galvanostatic curve of the composite $(\mathrm{Ti} / \mathrm{Sn} / \mathrm{Sb}) / \mathrm{Li}$ is presented for comparison (Fig. 3c).

\section{The first discharge profile}

The discharge profiles for the three materials start with the same shape; a rapid decrease of the potential down to $0.8 \mathrm{~V}$, where appears a more or less defined plateau. At this potential range, $\mathrm{Li}$ reacts with carbon black for all the materials and with the antimony for the composite $(\mathrm{Ti} / \mathrm{Sn} / \mathrm{Sb})$. For the latter, the length of the plateau corresponds to the lithiation of $\mathrm{Sb}$ into $\mathrm{Li}_{3} \mathrm{Sb}$. This reaction is also evidenced by the galvanostatic derivative curves (Fig. 3, right column) that show peaks of high intensity for the composite at $0.8 \mathrm{~V}$ compared to the curves of the BM- and MBATiSnSb samples which have lower intensities. The Ti/Sn/Sb composite profile differs also by the occurrence of well-defined voltage steps $(0.7,0.55$ and $0.4 \mathrm{~V})$ which are characteristic of the $\mathrm{Li} / \mathrm{Sn}$ alloying processes in metallic tin. The composite profile can then be seen as a combination of the $\mathrm{Sb}$ and $\mathrm{Sn}$ profiles. The discharge profile of BM powder exhibits another reaction at about $0.45 \mathrm{~V}$ that is not observed for BMA powder. Moreover, at about $0.25 \mathrm{~V}$, the BMA profile shows a better-defined plateau than the BM profile.

During the first discharge down to $0 \mathrm{~V}$, the voltage curves of the three materials (BM, BMA and composite) show the insertion of about 6.7 and $6.9 \mathrm{Li}$ per formula (theoretically $6.5 \mathrm{Li}$ according to the $\mathrm{Li}_{3} \mathrm{Sb}$ and $\mathrm{Li}_{7} \mathrm{Sn}_{2}$ phases formation) at a $C / 10$ cycling rate. If antimony is assumed to react with $3 \mathrm{Li}$, this is a first indication on the amount of lithium reacting with tin $(\sim 3.5$ Li) suggesting the formation of $\mathrm{Li}_{7} \mathrm{Sn}_{2}$ rather than $\mathrm{Li}_{22} \mathrm{Sn}_{4}$. The observed extra capacity of 0.2 to $0.4 \mathrm{Li}$ can be attributed to the SEI layer formation.

\section{The first charge profile}

As for the discharge, the Ti/Sn/Sb composite charge profile is again a combination of $\mathrm{Sb}$ and $\mathrm{Sn}$ profiles and looks completely

The cells made of BM and BMA powder show poor capacity retention since the capacity drops down to $200 \mathrm{~mA} \mathrm{~h} \mathrm{~g}^{-1}$ after only 20 cycles. Today, the huge influence of the architecture of the composite electrode on electrochemical behaviour has begun to be well established, then to enhance the cycling performances as well as the rate capability; polymeric electrodes were made using $\mathrm{CMC} / \mathrm{CB}$ as binder/conductive additive. ${ }^{30}$ The obtained results are summarized in Fig. 4b. A $500 \mathrm{~mA} \mathrm{~h} \mathrm{~g}^{-1}$ specific

a)
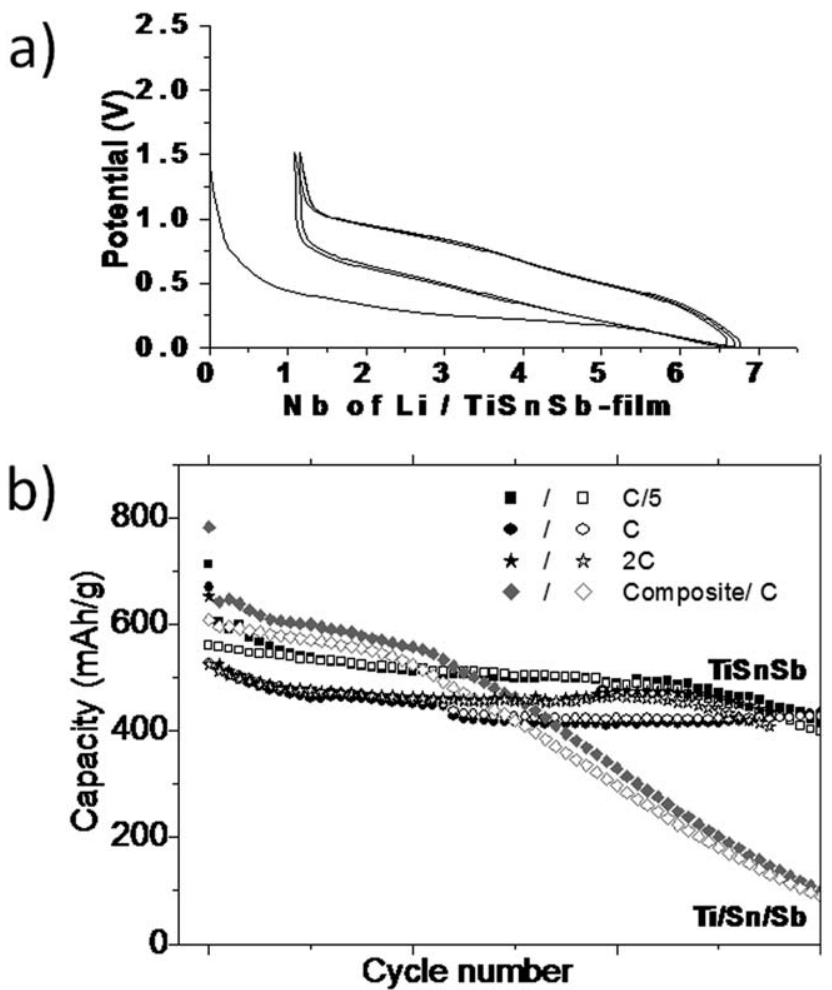

Fig. 4 a) Galvanostatic curve for [(BMA-TiSnSb)/CB/CMC (70/12/18) films/Li] cells cycled at $C / 5$ rate between 1.5 and $0 \mathrm{~V}$ and (b) corresponding capacity retention at various cycling rates. Curves (in gray line) obtained for the $\mathrm{Ti} / \mathrm{Sn} / \mathrm{Sb}$ composite cell are shown for comparison. Filled and opened symbols are the capacities on discharge and on charge respectively. 
capacity is maintained during 60 cycles at $2 \mathrm{C}$ rate $\left(2 \mathrm{Li} \mathrm{h}^{-1}\right)$. Note that the polarization (defined as half the potential difference between $1^{\text {st }}$ charge and $2^{\text {nd }}$ discharge at half capacity) is slightly decreased when the CMC-polymeric film is used (Fig. 4a) compared to powdered electrodes (Fig. 3a and b). Moreover, the $\mathrm{TiSnSb} / \mathrm{CMC} / \mathrm{CB}$ shows an excellent Coulombic efficiency demonstrating that a small amount of electrons/lithium ions is trapped in secondary parasitic reactions that can be caused by electrolyte degradation. It is noteworthy that the capacity retention is not much affected by the cycling-rate since $90 \%, 88 \%$ and $86 \%$ of the specific capacity is retained for the TiSnSb films during 60 cycles at $2 \mathrm{C}, \mathrm{C}, \mathrm{C} / 5$ respectively (Fig. 4b), while the fading is dramatic after 10 cycles at low rate with the Ti/Sn/Sb electrode. Surprisingly the slower cycling $(\mathrm{C} / 5)$ of the TiSnSb film shows a rapid fading after 60 cycles, which can be attributed to the aging of the cell after 5 months.

\section{XRD in situ operando analysis}

To grasp more insight into the electrochemical mechanism, operando X-ray diffraction studies were undertaken along the first discharge for BM and BMA-TiSnSb cells, Fig. 5a and $\mathrm{b}$ respectively. Up to the $x=1.2$ lithiation, the XRD patterns of both samples remain unchanged showing that the electrochemical activity observed in this range is related to the reaction of Li with electrolyte with the Solid Electrolyte Interphase (SEI) formation. Starting from $x=1.4 \mathrm{Li}$, the change on the patterns shape is significant since the TiSnSb peaks intensities (indicated by circles) decrease continuously and disappear completely at the end of the discharge (Fig. 5a and 5b). Simultaneously to the disappearance of $\mathrm{TiSnSb}$ a continuous shift of these $\mathrm{TiSnSb}$ peaks is observed to higher angles (Fig. 6a and 6b), corresponding to a decrease of the cell volume from 1044 to $1030 \AA^{3}$ for the BMA-TiSnSb. The shift and disappearance of the TiSnSb peaks is associated to the growth of very "broad peaks" in two $2 \theta$

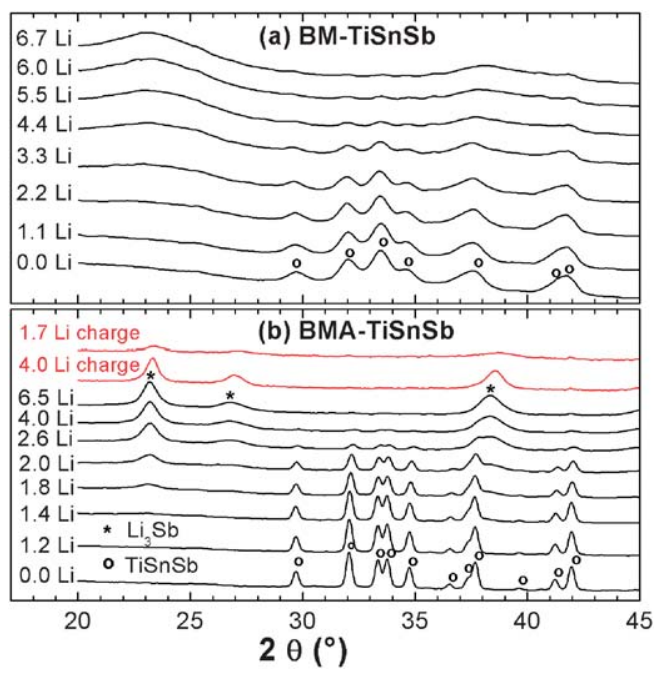

Fig. 5 In situ XRD patterns collected at various stages of discharge of (a) a BM-TiSnSb/Li and (b) BMA-TiSnSb/Li electrochemical cells cycled between 0 and $1.5 \mathrm{~V}$ at a $C / 5$ rate. Asterisks and circles were used to indicate the Bragg peaks corresponding to the $\mathrm{Li}_{3} \mathrm{Sb}$ and $\mathrm{TiSnSb}$ respectively.
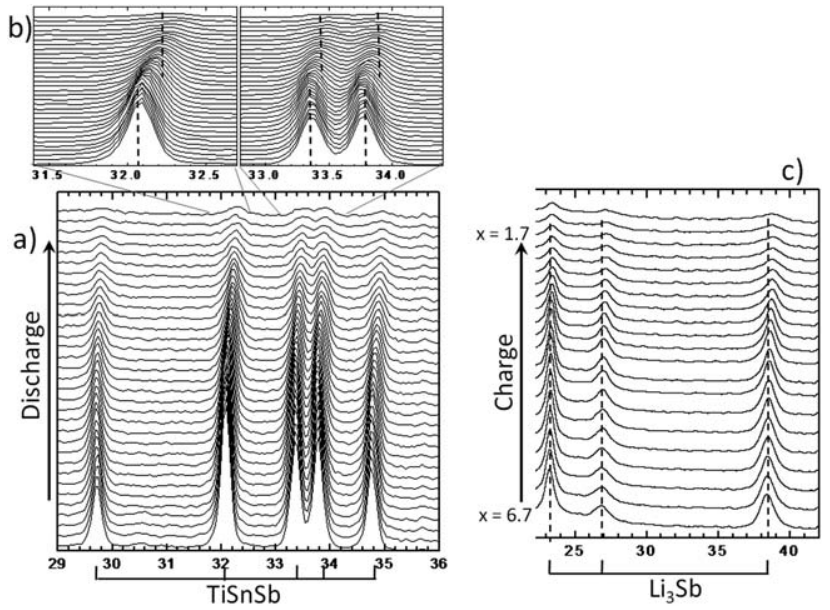

Fig. 6 Close-up view of the in situ XRD pattern of the BMA-TiSnSb/Li cell in the (a) $29-36^{\circ}$, (b) $31.5-32.5^{\circ}$ and $33-34.5^{\circ}$ angular regions on discharge and (c) $23-42^{\circ}$ angular region on charge.

regions $20-26^{\circ}$ and $36-40^{\circ}$. From their central position $\left(23.5^{\circ}\right.$ and $28.8^{\circ}$ ), those diffusion peaks can be attributed to the cubic $\beta-\mathrm{Li}_{3} \mathrm{Sb}(a=6.572 \AA, F m 3 m){ }^{31}$ Surprisingly, this phase is reported to be stable above $650{ }^{\circ} \mathrm{C}$. In our working conditions we would expect the formation of low temperature form $\alpha-\mathrm{Li}_{3} \mathrm{Sb}$ (hexagonal form). This phenomenon has already been observed in previous works. ${ }^{11,32}$

It is worth noting that the XRD pattern of $\mathrm{Li}_{3} \mathrm{Sb}$ formed in the discharge of the BM electrode is much more diffuse than the one of the discharged-BMA electrode, showing the impact of the crystallinity of the starting electrode into the discharged electrode. Finally, XRD analysis does not detect any trace of $\mathrm{Li}_{2} \mathrm{Sb}$ which is may be metastable at ambient temperature or kinetically less favorable than $\mathrm{Li}_{3} \mathrm{Sb}$ alloy as suggested by Xie et al. ${ }^{4}$ For the both BMA and BM samples, we could not spot any sign of Bragg peaks corresponding to the growth of metallic Ti that likely forms nanoparticles. Using HRTEM Park and Sohn have recently evidenced the formation of Ti nanoparticles during the electrochemical conversion of $\mathrm{TiSb}_{2} \cdot{ }^{33}$

When the BMA cell is charged, the $\mathrm{Li}_{3} \mathrm{Sb}$ Bragg peaks progressively decrease down to complete disappearance (Fig. 6c). As for the $\mathrm{TiSnSb}, \mathrm{Li}_{3} \mathrm{Sb}$ Bragg peaks shift up to higher angles during the charge. The XRD pattern for the fully charged BMA sample shows broad and diffuse peaks, characteristic of an amorphous or nano-sized material.

Upon subsequent cycles, in situ X-ray cell shows similar behaviors with, namely, the growth of $\mathrm{Li}_{3} \mathrm{Sb}$ during discharge and its disappearance during charge. At first sight, this is indicative of a conversion reaction process of TiSnSb into $\mathrm{Li}_{3} \mathrm{Sb}$ and Ti nanoparticles not visible by XRD.

\section{${ }^{119}$ Sn Mössbauer in situ operando analysis}

At this point of the study, no information about tin reactivity has been obtained by XRD analysis since no known $\mathrm{Li}-\mathrm{Sn}$ intermetallic phase has been evidenced from the XRD patterns. ${ }^{119} \mathrm{Sn}$ Mössbauer spectroscopy has the advantage of being sensitive (and selective) to tin compounds. It was then used in the operando mode to follow the reactivity of tin while cycling the TiSnSb 
powder. The charge/discharge curves have been carried out in a rate of $C / 5$ and Mössbauer spectra have been recorded each 85 min corresponding to the reaction of $0.28 \mathrm{Li}$. The fitted Mössbauer spectra obtained during the first discharge and charge of the BM powder are given in Fig. 7a and b. The BMA powder has also been studied and found to give similar spectra.

The spectra have been fitted using a model that combines the following components (illustrated in Fig. 7c and d):

- A main doublet for TiSnSb with the parameters given above that has been kept constrained for the fit of the spectra recorded during the first discharge. During the charge, this component is replaced by a new one with significantly different parameters $(\delta=$ $2.19, \Delta=1.70 \mathrm{~mm} \mathrm{~s}^{-1}$ ) indicating the formation a new Sn-based phase during the charge. This new phase seems to react reversibly with $\mathrm{Li}$ in the subsequent cycles.

- A second doublet corresponding to the impurity $\mathrm{SnSb}$ that has been found to be electrochemically active and to disappear definitively after the reaction of about $2 \mathrm{Li}$ during the first discharge.

- A third doublet related to Li-Sn intermetallics formed by the reaction of $\mathrm{Li}$ with $\mathrm{TiSnSb}$. This "phase" (more likely a mixture of Li-Sn intermetallics) appears in the first discharge just after the SEI domain and exhibits hyperfine parameters that change as a function of the amount of the reacted lithium, for this reason it will be noted as $\mathrm{Li}_{x} \mathrm{Sn}$. The Mössbauer parameters of this "phase" are also found to change in a reversible way during charges and discharges.

During the first discharge (Fig. 7a), the Mössbauer spectra start to exhibit significant changes only after the reaction of about 1.1 $\mathrm{Li}$ confirming that the observed electrochemical activity in this range is related to the reaction of $\mathrm{Li}$ with electrolyte and/or some surface phenomena (SEI). The changes consist of the appearance of a new Mössbauer absorption (doublet) having hyperfine parameters in the range of Li-Sn intermetallics. Even though this new doublet cannot be unequivocally attributed to one single $\mathrm{Li}-$ Sn intermetallic, the evolution of the average isomer shift $(\langle\delta\rangle)$ is a good indicator of the Li content in the formed phases. In fact, Robert et al. have established that $\langle\delta\rangle$ decreases linearly as the $\mathrm{Li}$ content increases. ${ }^{34}$

At the beginning of the discharge, the high $\langle\delta\rangle\left(\sim 2.25 \mathrm{~mm} \mathrm{~s}^{-1}\right)$ indicates the formation of Sn-rich, typically in the range of LiSn and $\mathrm{Li}_{7} \mathrm{Sn}_{3}$ intermetallics. Further reaction of lithium induces a decrease of $\langle\delta\rangle$ in accordance with Li-enrichment. At the end of the discharge, $\langle\delta\rangle$ reaches $1.9 \mathrm{~mm} \mathrm{~s}^{-1}$ indicating the formation of $\mathrm{Li}_{7} \mathrm{Sn}_{2}$. At this point, the spectrum of the BM-cell can be reasonably fitted using the two components of $\mathrm{Li}_{7} \mathrm{Sn}_{2}$ expected from the lattice structure (Fig. 8a), the observed misfit can be explained by the distortion of the tin environment in the formed phase. Interestingly, the spectrum obtained at the end of discharge of the BMA-cell (Fig. 8b) does not show any misfit indicating the formation of a more ordered $\mathrm{Li}_{7} \mathrm{Sn}_{2}$ lattice. Fig. 9

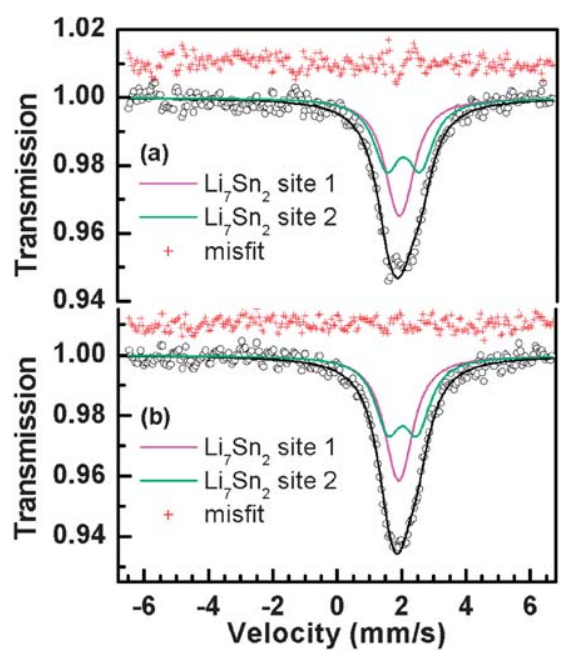

Fig. 8 In situ Mössbauer spectra collected at the end of discharge of (a) $\mathrm{BM}-\mathrm{TiSnSb} / \mathrm{Li}$ and (b) BMA-TiSnSb/Li electrochemical cells cycled between 0 and $1.5 \mathrm{~V}$.
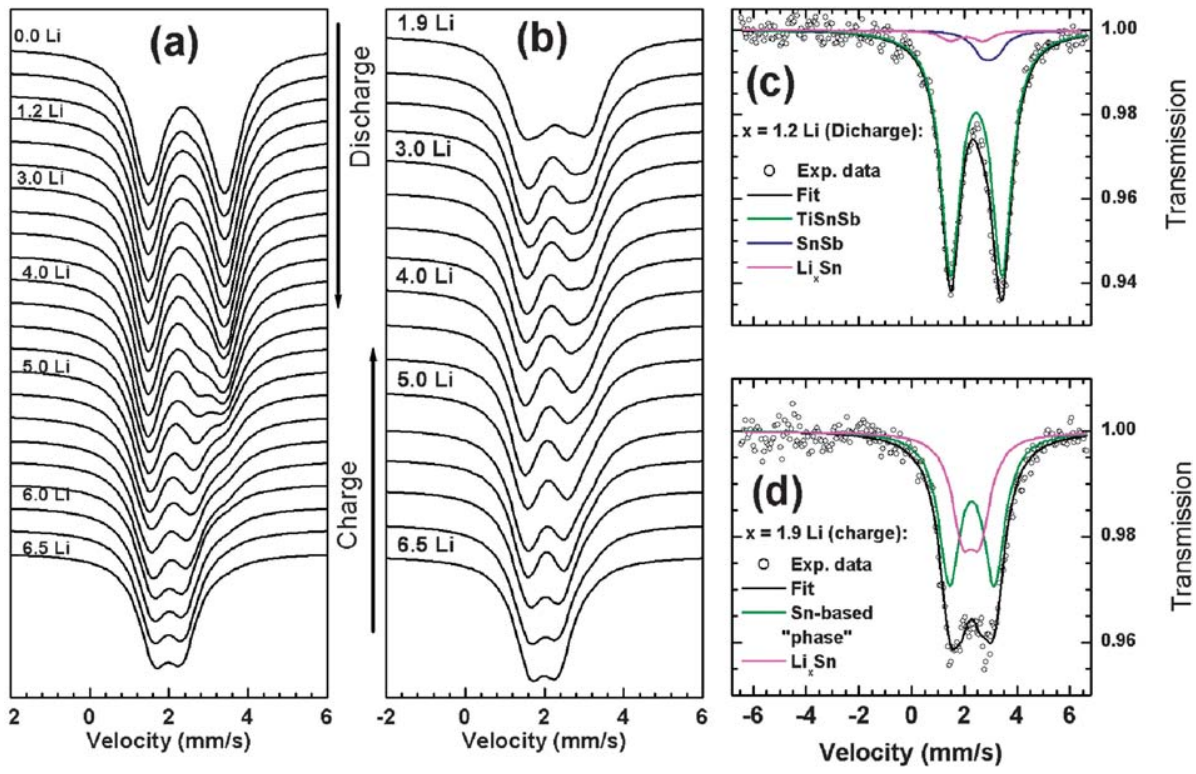

Fig. 7 Operando Mössbauer spectra collected at various stages (a) of discharge and (b) of charge of TiSnSb-BM/Li electrochemical cell cycled between 0 and $1.5 \mathrm{~V}$. In (c) the fitted spectrum recorded at $x=1.2$ on discharge and in (d) the fitted spectrum recorded at $x=1.9$ on charge. 


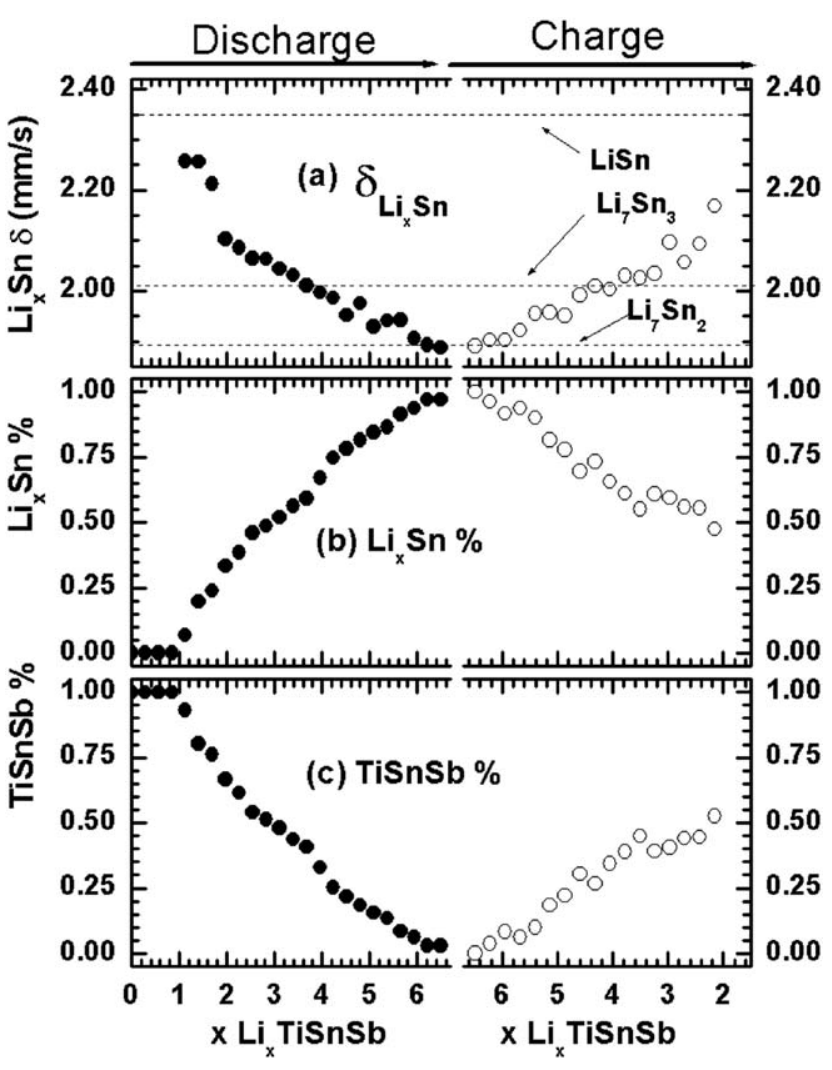

Fig. 9 Evolution versus the number of lithium atoms per TiSnSb vs. of the average isomer shift of the $\mathrm{Li}_{x} \mathrm{Sn}$ phases (a), the relative amount of $\mathrm{Li}_{x} \mathrm{Sn}$ (b) and TiSnSb (c) (determined by Mössbauer spectroscopy).

shows also the relative amounts of $\mathrm{TiSnSb}$ and $\mathrm{Li}_{x} \mathrm{Sn}$ phases versus the lithium amount in the TiSnSb/Li cell. The results clearly demonstrate the formation of $\mathrm{Li}_{x} \mathrm{Sn}$, correlated to the disappearance of $\mathrm{TiSnSb}$, during the first discharge, according to the following reaction (taking into account $\mathrm{Sb}$ reaction, deduced from XRD data):

$$
\mathrm{TiSnSb}+6.5 \mathrm{Li} \rightarrow \mathrm{Ti}+\mathrm{Li}_{3} \mathrm{Sb}+0.5 \mathrm{Li}_{7} \mathrm{Sn}_{2}
$$

$\mathrm{Li}_{x} \mathrm{Sn}$ average isomer shift shows a reversible variation during the charge (Fig. 9a) since it increases linearly with the extraction of lithium. It does not however reach the starting value $(2.25 \mathrm{~mm}$ $\mathrm{s}^{-1}$ ) suggesting an incomplete extraction of lithium in accordance with the observed irreversible capacity. Note that the incomplete reconversion is confirmed by the $\%$ of $\mathrm{Li}_{x} \mathrm{Sn}$ at the end of charge close to 45 . When TiSnSb electrodes are charged, we also observe a gradual conversion of $\mathrm{Li}_{x} \mathrm{Sn}$ into a new Sn-based phase with an isomer shift and a quadrupole splitting of respectively $2.19 \mathrm{~mm}$ $\mathrm{s}^{-1}$ and $1.70 \mathrm{~mm} \mathrm{~s}^{-1}$. These parameters, that remain constant during the subsequent cycles, are clearly not those of metallic tin $\left(\delta=2.54 \mathrm{~mm} \mathrm{~s}^{-1}\right.$ and $\left.\Delta=0.29 \mathrm{~mm} \mathrm{~s}^{-1}\right)$ nor those of TiSnSb. The isomer shift value of this new phase is in the range of $\operatorname{Sn}(0)$, whereas its high quadrupole splitting is indicative of a lattice structure where tin atoms environment is highly distorted. For these reasons, we can conclude that the new phase formed in the charge is a Sn-based intermetallic in a nanometric or amorphous form.
With regard to the available metals during the charge ( $\mathrm{Ti}, \mathrm{Sb}$ and $\mathrm{Li}$ ), tin can form binary alloys as $\mathrm{Sn}-\mathrm{Sb}$ or $\mathrm{Ti}-\mathrm{Sn}$. It can also contribute to a more complicated ternary or quaternary phases containing $\mathrm{Ti}, \mathrm{Sb}$ and $\mathrm{Li}$. To our knowledge, Mössbauer data are only known for $\mathrm{SnSb}$, and 5 intermetallics in the $\mathrm{Ti}-\mathrm{Sn}$ system. ${ }^{35,36}$ Among the intermetallics for which Mössbauer parameters are known, $\mathrm{Ti}_{2} \mathrm{Sn}_{3}{ }_{3}^{35,36}$ seems to have the closest parameters $\left(\langle\delta\rangle=2.196 \mathrm{~m} \mathrm{~s}^{-1},\langle\Delta\rangle=2.00 \mathrm{~mm} \mathrm{~s}^{-1}\right)$ to those of the new phase $\left(\delta=2.19, \Delta=1.70 \mathrm{~mm} \mathrm{~s}^{-1}\right)$. Even though the available Mössbauer data suggest the formation of $\mathrm{Ti}_{2} \mathrm{Sn}_{3}$ intermetallic, the presence of other phases cannot be excluded. The identification of the formed phases is rendered more complicated by the fact that compounds formed during the electrochemical extraction of $\mathrm{Li}$ have distorted structures and may enclose other elements present in the electrode.

Assuming the formation of Ti-Sn during the charge, there remains a question: what does happen to the $\mathrm{Sb}$ released from $\mathrm{Li}_{3} \mathrm{Sb}$ ? In one hand, the shape of the TiSnSb potential profile can exclude the formation of $\mathrm{Sb}$ since no characteristic plateau is observed (which is the case for $\mathrm{Ti} / \mathrm{Sn} / \mathrm{Sb}$ composite). In the other hand, Mössbauer spectra indicate that $\mathrm{SnSb}$ is not formed during the charge. Sb is then likely alloyed with $\mathrm{Ti}$ to form one of the Ti$\mathrm{Sb}$ system intermetallics. Many Ti-Sb compounds such as TiSb, $\mathrm{TiSb}_{2}$ have been reported. ${ }^{37,38}$ The charge of the TiSnSb cell can then be summarized in two reactions:

$$
\begin{gathered}
a \mathrm{Ti}+\mathrm{Li}_{x} \mathrm{Sn} \rightarrow \mathrm{Ti}_{a} \mathrm{Sn}+x \mathrm{Li} \\
b \mathrm{Ti}+\mathrm{Li}_{3} \mathrm{Sb} \rightarrow \mathrm{Ti}_{b} \mathrm{Sb}+3 \text { Liwith } a+b \approx 1
\end{gathered}
$$

It is also possible that the charge process produces a ternary phase as follows

$$
\mathrm{Ti}+\mathrm{Li}_{x} \mathrm{Sn}+\mathrm{Li}_{3} \mathrm{Sb} \rightarrow \text { "Ti-Sb-Sn" }+(3+x) \mathrm{Li}
$$

To figure out which equation [(eqn (2) and (3)) or (4)] occurs in reality, further investigations are required, especially ${ }^{121} \mathrm{Sb}$ Mössbauer spectroscopy and HRTEM analyses. Another aspect can be underlined, despite the Ti/Sn/Sb composite (as well as $\mathrm{Sn} /$ $\mathrm{SnSb}$ composite) has been found to form the same phases as $\mathrm{TiSnSb}\left(\mathrm{Li}_{3} \mathrm{Sb}\right.$ and $\left.\mathrm{Li}_{7} \mathrm{Sn}_{2}\right)$ at the end of discharge, their charge processes are completely different. Contrary to the $\mathrm{Ti} / \mathrm{Sn} / \mathrm{Sb}$ composite, the charge of TiSnSb alloy does not produce any metallic $\mathrm{Sn}$ and $\mathrm{Sb}$ particles.

\section{Concluding remarks}

Contrary to what has been reported for binary or ternary $-\mathrm{Sn}$, -Sb composites ${ }^{39-41}$ and according to the in situ X-ray and Mössbauer data, $\mathrm{Sn}$ and $\mathrm{Sb}$ react with Li simultaneously upon first discharge of TiSnSb and no preferential reaction can be evidenced. Concerning titanium, although none of the analytical techniques employed provide unequivocal evidence as to its nature in the discharged electrode, we expect it to behave as all the inactive metals reported in the literature for conversion materials, i.e. to form nano- and/or amorphous metallic particles $\left(\mathrm{Co},{ }^{4} \mathrm{Ti}^{33}{ }^{33} \mathrm{Fe},{ }^{42}\right.$ etc. $)$.

$\mathrm{The} \mathrm{Ti} / \mathrm{Sn} / \mathrm{Sb}$ composite discharge mechanism has been found to be similar to that reported for $\mathrm{Sn} / \mathrm{SnSb}$ or $\mathrm{Cu} / \mathrm{Sn} / \mathrm{Sb}$ 
composites showing potential steps corresponding to the successive lithiations of $\mathrm{Sb}$ and $\mathrm{Sn}$ into $\mathrm{Li}_{3} \mathrm{Sb}$ and $\mathrm{Li}_{7} \mathrm{Sn}_{2}$ respectively. Through a very different electrochemical process, the $1^{\text {st }}$ discharge of TiSnSb produces the same $\mathrm{Sb}$ - and $\mathrm{Sn}$-based alloys as the composites discussed. The charge profiles as well as the species identified in the charged electrode of TiSnSb appear to be completely different with no evidence of metallic Sb or Sn. It was previously suggested for the binary and ternary composites that the reaction of all active components ( $\mathrm{Sn}, \mathrm{Sb}$ ) with $\mathrm{Li}$ at different potentials in the charging/discharging process leads to both gradual volume change and accommodation of the strain yielded by the reacted phase by the unreacted component. ${ }^{13,43}$ However all the composites and also $\mathrm{Ti} / \mathrm{Sn} / \mathrm{Sb}$ fade rapidly and much faster than the TiSnSb/Li (Fig. 4, inset). These different electrochemical behaviors of two similar chemical composition electrodes demonstrate that the structural feature of the pristine material clearly affects both the mechanism involved during the cycling and the corresponding performance. At this step, the question is opened on the role of Ti on the mechanism.

Finally, the capacity retention as well as the rate capability are highly improved in the $\mathrm{TiSnSb}$ regarding the performance of other ternary $\mathrm{Ti} / \mathrm{Sn} / \mathrm{Sb}$ or $\mathrm{Sn} / \mathrm{Sb} / \mathrm{M}$ composites. The performance enhancement inheres in the material as well as in the electrode formulation with suitable carbon additive and binder.

\section{Acknowledgements}

This research was performed in the framework of the ALISTORE European Research Institute and the Mössbauer platform. Authors thank C. Marino (ICG-AIME) and B. Lestriez (IMN) for help on the electrode composite preparation. Authors are grateful to Dr R. P. Hermann for providing Mössbauer fitting software.

\section{References}

1 P. G. Bruce, B. Scrosati and J.-M. Tarascon, Nanomaterials for rechargeable lithium batteries, Angew. Chem., Int. Ed., 2008, 47(16), 2930-2946

2 M. R. Palacin, Recent advances in rechargeable battery materials: a chemist's perspective, Chem. Soc. Rev., 2009, 38(9), 2565-2575.

3 L. M. L. Fransson, J. T. Vaughey, K. Edstrom and M. M. Thackeray, Structural transformations in intermetallic electrodes for lithium batteries, J. Electrochem. Soc., 2003, 150(1), A86-A91.

4 J. Xie, X. Zhao, G. Cao, Y. Zhong and M. Zhao, Ex-situ XRD studies of $\mathrm{CoSb}_{3}$ compound as the anode material for lithium ion batteries, $J$. Electroanal. Chem., 2003, 542, 1-6.

5 J. Xie, G. Cao, Y. Zhong and X. B. Zhao, Capacity fade mechanism of $\mathrm{CoSb}_{3}$ intermetallic compound, J. Electroanal. Chem., 2004, 568, 323-327.

6 L. Monconduit, J. C. Jumas, R. Alcántara, J. L. Tirado and C. Pérez Vicente, Evaluation of discharge and cycling properties of skutterudite-type $\mathrm{Co}_{1-2 y} \mathrm{Fe}_{y} \mathrm{Ni}_{y} \mathrm{Sb}_{3}$ compounds in lithium cells, $J$. Power Sources, 2002, 107(1), 74-79.

7 R. J. Alcantara, F. Fernandez-Madrigal, P. L. Lavela, J. Tirado, J. Claude Jumas, and J. Olivier-Fourcade, electrochemical reaction of lithium with the $\mathrm{CoSb}_{3}$ skutterudite, J. Mater. Chem., 1999, 9 (10), 2517-2521.

8 J. Wolfenstine, S. Campos, D. Foster, J. Read and W. K. Behl, Nanoscale $\mathrm{Cu}_{6} \mathrm{Sn}_{5}$ anodes, J. Power Sources, 2002, 109(1), 230-233.

9 Q. F. Dong, C. Z. Wu, M. G. Jin, Z. C. Huang, M. S. Zheng, J. K. You and Z. G. Lin, Preparation and performance of nickeltin alloys used as anodes for lithium-ion battery, Solid State Ionics, 2004, 167(1-2), 49-54.

10 L. Fang and B. V. R. Chowdari, Sn-Ca amorphous alloy as anode for lithium ion battery, J. Power Sources, 2001, 97-98, 181-184.
11 C. Villevieille, C. M. Ionica-Bousquet, B. Ducourant, J. C. Jumas and L. Monconduit, $\mathrm{NiSb}_{2}$ as negative electrode for Li-ion batteries: an original conversion reaction, J. Power Sources, 2007, 172(1), 388-394.

12 X. Z. Liao, Z. F. Ma, H. H. Hu, Y. Z. Sun and X. X. Yuan, SnNideposited carbonaceous mesophase spherule as anode material for lithium ion batteries, Electrochem. Commun., 2003, 5(8), 657-661.

$13 \mathrm{M}$. Wachtler, J. O. Besenhard and M. Winter, Tin and tin-based intermetallics as new anode materials for lithium-ion cells, J. Power Sources, 2001, 94(2), 189-193.

14 S. A. Needham, G. X. Wang and H. K. Liu, Electrochemical performance of $\mathrm{SnSb}$ and $\mathrm{Sn} / \mathrm{SnSb}$ nanosize powders as anode materials in Li-ion cells, J. Alloys Compd., 2005, 400(1-2), 234-238.

15 L. H. Shi, H. Li, Z. X. Wang, X. J. Huang and L. Q. Chen, Nano$\mathrm{SnSb}$ alloy deposited on MCMB as an anode material for lithium ion batteries, J. Mater. Chem., 2001, 11(5), 1502-1505.

16 H. Li, Q. Wang, L. H. Shi, L. Q. Chen and X. J. Huang, Nanosized $\mathrm{SnSb}$ alloy pinning on hard non-graphitic carbon spherules as anode materials for a Li ion battery, Chem. Mater., 2002, 14(1), 103-108.

17 S. D. Beattie and J. R. Dahn, Combinatorial electrodeposition of ternary $\mathrm{Cu}-\mathrm{Sn}-\mathrm{Zn}$ alloys, J. Electrochem. Soc., 2005, 152(8), C542C548.

18 T. Tabuchi, N. Hochgatterer, Z. Ogumi and M. Winter, Ternary Sn$\mathrm{Sb}-\mathrm{Co}$ alloy film as new negative electrode for lithium-ion cells, $J$. Power Sources, 2009, 188(2), 552-557.

19 R. Yang, J. Huang, W. Zhao, W. Z. Lai, X. Z. Zhang, J. Zheng and X. G. Li, Bubble assisted synthesis of $\mathrm{Sn}-\mathrm{Sb}-\mathrm{Cu}$ alloy hollow nanostructures and their improved lithium storage properties, $J$. Power Sources, 2010, 195(19), 6811-6816.

20 H. Guo, H. Zhao, X. Jia, J. He, W. Qiu and X. Li, A novel $\mathrm{Sn}_{x} \mathrm{SbNi}$ composite as anode materials for Li rechargeable batteries, J. Power Sources, 2007, 174(2), 921-926.

21 B. Malaman and J. Steinmetz, Deux nouveaux ternaires à structures apparentées: TiSnSb de type $\mathrm{CuMg}_{2}$ et $\mathrm{NbSnSb}$ de type $\mathrm{CuAl}_{2}, J$. Less-Common Met., 1979, 65(2), 285-288.

22 C. Frontera and J. Rodríguez-Carvajal, FP as a new tool for flipping ratio analysis, Phys. B (Amsterdam, Neth. ), 2003, 335(1-4), 219-222.

23 J. B. Leriche, S. Hamelet, J. Shu, M. Morcrette, C. Masquelier, G. Ouvrard, M. Zerrouki, P. Soudan, S. Belin, E. Elkaim and F. Baudelet, An electrochemical cell for operando study of lithium batteries using synchrotron radiation, J. Electrochem. Soc., 2010, 157(5), A606-A610.

$24 \mathrm{E}$. Dashjav and $\mathrm{H}$. Kleinke, $\mathrm{Sn} / \mathrm{Sb}$ atom ordering in the ternary stannide-antimonide TiSnSb, J. Solid State Chem., 2003, 176(2), 329-337.

25 M. T. Sougrati; M. El Khalifi; P. E. Lippens; J. Fullenwarth; B. Fraisse; L. Monconduit; J. C. Jumas, Experimental and theoretical Mössbauer study of TiSnSb, to be published.

26 J. Cabana, L. Monconduit, D. Larcher and M. R. Palacin, Beyond intercalation-based Li-ion batteries: the state of the art and challenges of electrode materials reacting through conversion reactions, Adv. Mater., 2010, 22(35), E170-E192.

27 P. Poizot, S. Laruelle, S. Grugeon, L. Dupont and J. M. Tarascon, Nano-sized transition-metaloxides as negative-electrode materials for lithium-ion batteries, Nature, 2000, 407(6803), 496-499.

28 S. Boyanov, D. Zitoun, M. Menetrier, J. C. Jumas, M. Womes and L. Monconduit, Comparison of the electrochemical lithiation/ delitiation mechanisms of $\mathrm{FeP}_{x}(x=1,2,4)$ based electrodes in Liion batteries, J. Phys. Chem. C, 2009, 113(51), 21441-21452.

29 F. Gillot, S. Boyanov, L. Dupont, M. L. Doublet, M. Morcrette, L. Monconduit and J. M. Tarascon, Electrochemical reactivity and design of $\mathrm{NiP}_{2}$ negative electrodes for secondary Li-ion batteries, Chem. Mater., 2005, 17(25), 6327-6337.

30 D. Guy, B. Lestriez and D. Guyomard, New composite electrode architecture and improved battery performance from the smart use of polymers and their properties, Adv. Mater., 2004, 16(6), 553.

31 M. E. Leonova, I. K. Bdikin, S. A. Kulinich, O. K. Gulish, L. G. Sevast'yanova and K. P. Burdina, High-pressure phase transition of hexagonal alkali pnictides, Inorg. Mater., 2003, 39(3), 266-270.

32 C. Villevieille, B. Fraisse, M. Womes, J. C. Jumas and L. Monconduit, A new ternary $\mathrm{Li}_{4} \mathrm{FeSb}_{2}$ structure formed upon discharge of the $\mathrm{FeSb}_{2} /$ Li cell, J. Power Sources, 2009, 189(1), 324-330.

33 C.-M. Park and H.-J. Sohn, Electrochemical characteristics of $\mathrm{TiSb}_{2}$ and $\mathrm{Sb} / \mathrm{TiC} / \mathrm{C}$ nanocomposites as anodes for rechargeable Li-ion batteries, J. Electrochem. Soc., 2010, 157(1), A46-A49. 
34 F. Robert, P. E. Lippens, J. Olivier-Fourcade, J. C. Jumas, F. Gillot, M. Morcrette and J. M. Tarascon, Mössbauer spectra as a "fingerprint" in tin-lithium compounds: applications to Li-ion batteries, J. Solid State Chem., 2007, 180(1), 339-348.

35 J. W. O'Brien, R. A. Dunlap and J. R. Dahn, A Mössbauer effect and $\mathrm{X}$-ray diffraction investigation of Ti-Sn intermetallic compounds: I. Equilibrium phases, J. Alloys Compd., 2003, 353(1-2), 60-64.

36 J. W. O'Brien, R. A. Dunlap and J. R. Dahn, A Mössbauer effect and $\mathrm{X}$-ray diffraction investigation of Ti-Sn intermetallic compounds: II. Nanostructured phases prepared by ball milling with $\mathrm{Al}_{2} \mathrm{O}_{3}$ and TiN, J. Alloys Compd., 2003, 353(1-2), 65-73.

37 A. Kjekshus, F. Gronvold and J. Thorbjornsen, On phase relationships in titanium-antimony system-crystal structures of $\mathrm{Ti}_{3} \mathrm{sb}$, Acta Chem. Scand., 1962, 16(6), 1493.

38 H. Okamoto, Sn-Ti (tin-titanium), J. Phase Equilib. Diffus., 2010, 31 (2), 202-203.

39 I. Rom, M. Wachtler, I. Papst, M. Schmied, J. O. Besenhard, F. Hofer and M. Winter, Electron microscopical characterization of $\mathrm{Sn} / \mathrm{SnSb}$ composite electrodes for lithium-ion batteries, Solid State Ionics, 2001, 143(3-4), 329-336.

$40 \mathrm{M}$. Winter and J. O. Besenhard, Electrochemical lithiation of tin and tin-based intermetallics and composites, Electrochim. Acta, 1999, 45 (1-2), 31-50

41 F. J. Fernandez-Madrigal, P. Lavela, C. P. Vicente, J. L. Tirado, J. C. Jumas and J. Olivier-Fourcade, X-Ray diffraction, Li-7 MAS NMR spectroscopy, and Sn-119 Mössbauer spectroscopy study of SnSb-based electrode materials, Chem. Mater., 2002, 14(7), 29622968.

42 M. Chamas, P.-E. Lippens, J.-C. Jumas, K. Boukerma, R. Dedryvère, D. Gonbeau, J. Hassoun, S. Panero and B. Scrosati, Comparison between microparticles and nanostructured particles of $\mathrm{FeSn}_{2}$ as anode materials for Li-ion batteries, J. Power Sources, 2010, DOI: 10.1016/jpowsour.2010.09.113.

43 J. Yang, Y. Takeda, Q. Li, N. Imanishi and O. Yamamoto, Lithium insertion into $\mathrm{Sn}$ - and $\mathrm{SnSb}_{x}$-based composite electrodes in solid polymer electrolytes, J. Power Sources, 2000, 90(1), 64-69. 